\title{
Predicting Closed Price Time Series Data Using ARIMA Model
}

\author{
S. AL Wadi ${ }^{1}$, Mohammad Almasarweh ${ }^{2} \&$ Ahmed Atallah Alsaraireh $^{3}$ \\ ${ }^{1}$ Department of Risk Management and Insurance, Faculty of Management and Finance, The University of Jordan, \\ Aqaba, Jordan \\ ${ }^{2}$ Department of Business Administration, The University of Jordan, Aqaba, Jordan \\ ${ }^{3}$ Department of Computer Information Systems, The University of Jordan, Aqaba, Jordan \\ Correspondence: S. AL Wadi, Department of Risk Management and Insurance, Faculty of Management and \\ Finance, The University of Jordan, Aqaba, Jordan. E-mail: Sadam_alwadi@yahoo.co.uk
}

Received: May 10, 2018 Accepted: September 20, 2018 Online Published: October 29, 2018

doi:10.5539/mas.v12n11p181 URL: https://doi.org/10.5539/mas.v12n11p181

\begin{abstract}
Closed price forecasting plays a main rule in finance and economics which has encouraged the researchers to introduce a fit model in forecasting accuracy. The autoregressive integrated moving average (ARIMA) model has developed and implemented in many applications. Therefore, in this article the researchers utilize ARIMA model in predicting the closed time series data which have been collected from Amman Stock Exchange (ASE) from Jan. 2010 to Jan. 2018. As a result this article shows that the ARIMA model has significant results for short-term prediction. Therefore, these results will be helpful for the investments.
\end{abstract}

Keywords: short term forecasting, ARIMA model, closed Price time series

\section{Introduction}

Predicting remains a hot topic for researchers since the institutions are emphasis on two directions which are investment decision making and developing an effective strategy about their future work. Financial time series data specially stock market data is very hard in decomposition and forecasting because the data are non-linear and non-stationary with high heteroscedasticity (Tabachnick and Fidell, 2001; Pai and Lin, 2005; Wang, et al., 2012; Wei, 2013). The future plan of the investors is to improve their profits without risk. This issue encourages the researchers to develop many forecasting models (Tabachnick and Fidell, 2001; Atsalakis, et al., 2011) such as artificial neural network model (ANNs) for more details refer to (Tabachnick and Fidell, 2001; Mitra, 2009; Atsalakis and Kimon, 2009; Mohamed, 2010; Maqableh and Karajeh, 2014; Maqableh et al., 2015), some hybrid models have modified for more details refer to (Wang, 2011; Awajan et al., 2017). ARIMA model which is an old model but still has widely application in financial time series field (Kyungjoo, et al., 2007; Merh, et al., 2010; Sterba and Hilovska, 2010). This model is considered as the forecasting process and can be implemented from two steps which are statistical and artificial intelligence techniques (Tabachnick and Fidell, 2001). As a critically review, many models have been used in predicting such as exponential model, regression method, GARCH model and others. However, few related works that has used ARIMA model for forecasting stock market data for more details refer to (Meyler et al., 1998; Javier et al., 2003; Nochai \& Nochai, 2006; Khasel et al., 2009; Lee and Ho, 2011; Wang, 2011; Khashei et al., 2012). However, some researchers have used ARIMA model in forecasting some of financial data such as (Alwadi, 2015).

ARIMA model is a statistical method which used for decomposing and predicting time series data by modeling the correlations in the data. In real data application, there are some advantages of the ARIMA model especially short term predicting (Box and Jenkins, 1970). Moreover, the ARIMA method only needs the prior data of a time series data or stock market data to generalize the forecast. Hence, the ARIMA method can improve the forecast accuracy while stilling the number of parameters to a minimum. While, there are some disadvantages of the ARIMA model such as: in the model identification techniques for identifying the correct model from the class of possible models are hard or maybe undefined, the theoretical model of the ARIMA model and structural relationships are not distinct as some simple forecasts models such as simple exponential smoothing and Holt-Winters (Donovan, 1983). Finally, this model in the long term forecasting is poor model at predicting series with turning points. However, these disadvantages will not effect on the direction of this research.

In this article the researcher applying ARIMA model for short term closed stock market data and some results of 
forecasting are obtained. The results gotten from real data established the potential asset of ARIMA model to offer for the investors short-term forecasting that could assistance investment decision making. This article is organized as: Section 2 presents brief overview of mathematical models used. Section 3 presents the results obtained and the methodology used. Finally, in section 4 is the conclusion.

\section{Mathematical Models}

\subsection{Autoregressive Integrated Moving-Average Model (ARIMA $(p, d, q)$ )}

The auto-regressive moving average (ARMA) models are used in stationary stock market data only, this model contains three combination models which are (Awajan et al., 2017; Box and Jenkins, 1970):

1) autoregressive (AR) model and a moving average

2) (MA) model.

3) $\left\{\mathrm{e}_{+}\right\}$: white noise $(\mathrm{WN})$ process,

A time series $\left\{\mathbf{Y}_{\mathrm{t}}\right\}$ is said to follow the $\operatorname{ARMA}(\mathrm{p}, \mathrm{q})$ model if:

$$
Y_{\mathrm{t}}=\mathrm{i}+\phi_{1} Y_{:-1}+\phi_{2} \mathrm{Y}_{\mathrm{t}-2} \ldots+\phi_{\mathrm{p}} \mathrm{Y}_{\mathrm{t}-2}+\mathrm{e}_{\mathrm{t}}-\mathrm{e}_{1} \mathrm{e}_{\mathrm{t}-1}-\mathrm{e}_{\mathrm{z}} \mathrm{e}_{\mathrm{t}-2, \ldots}-\mathrm{e}_{\mathrm{q}} \mathrm{e}_{\mathrm{t}-\mathrm{q}}
$$

Where $\mathrm{p}$ and $\mathrm{q}$ are greater than zeros, prefers to autoregressive part (AR), $\mathrm{q}$ refers to moving part (MA) and $\left\{e_{t}\right\}$ is the white noise. An extension of the ordinary ARMA model is the auto-regressive integrated moving-average model (ARIMA $(\mathrm{p}, \mathrm{d}, \mathrm{q}))$ given by :

$$
\Phi_{p}(B)(1-B){ }^{d} Y_{t}=e_{0}+e_{q}(B) e_{t}
$$

Where $\mathrm{p}, \mathrm{d}$ and $\mathrm{q}$ denote orders of auto-regression, integration (differencing) and moving average, respectively. When $\mathrm{d}=0$, the ARIMA model reduces to the ordinary ARMA model

\subsection{Accuracy Criteria}

This section consists of two subsections. Firstly, we will present the criteria which have been used to make a fair comparison. The researchers have been adopted to compare the performance of the models within one type of accuracy criteria which is Root Mean Squared Error. For more details about the mathematical model refer to (Awajan et al., 2017; Jaber, et al., 2017).

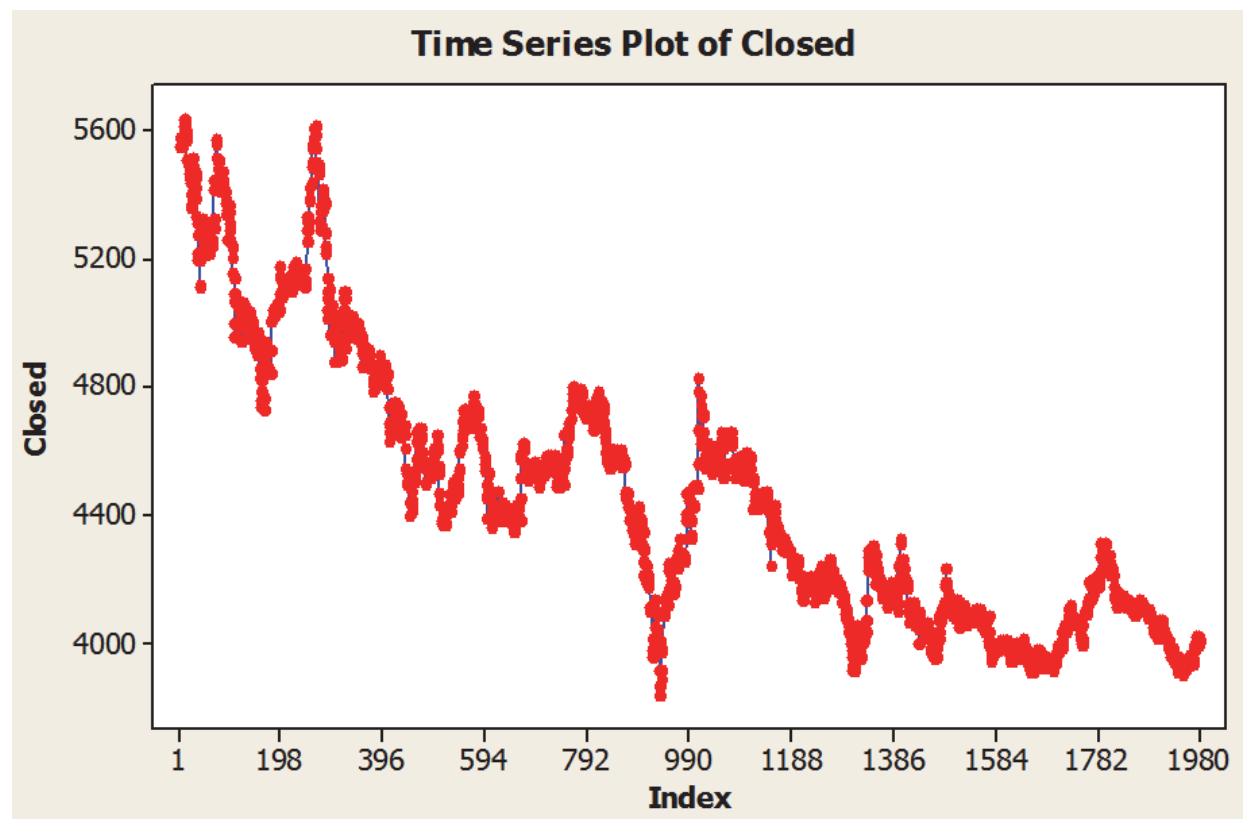

Figure 1. Diagram of the dataset 


\section{Methodology, Results and Discussion}

The methodology of this article is to use the fit ARIMA model for closed stock market data in order to implement a fitted forecasting model. The MINTAB software is the tool used to get the results. The daily price index of Amman Stock Exchange (ASE) for a specific period of time has been selected as the statistical population; about 2000 observations were accumulated for each variable from related databases in the mentioned period. Figure 1 shows the diagram of the dataset.

We notice that the data are non- stationary since it not fluctuated around constant mean and variance and there is some attractive events such as at the observations number: 198, 200, 250, 900, 1000 then the data become stable after the observation number1200 which indicate that the external variables are less effect than before the observation number 1200 .

To find the fitted ARIMA model. Therefore, RMSE is selected as criteria since there are many ARIMA models can be established for one column of dataset based on using different values of $\mathrm{p}, \mathrm{d}$ and $\mathrm{q}$. Therefore, the fitted ARIMA model has less RMSE. The following Table will show all the possible fitted ARIMA models with its RMSE.

Table 1. Possible ARIMA models with its RMSE

\begin{tabular}{|c|c|c|c|c|c|c|c|c|c|c|}
\hline \multicolumn{2}{|c|}{ ARIMA } & \multirow{2}{*}{$\begin{array}{l}\text { RMSE } \\
\text { Not fitted }\end{array}$} & \multicolumn{3}{|c|}{ ARIMA } & \multirow{2}{*}{$\frac{\text { RMSE }}{\text { Not fitted }}$} & \multicolumn{3}{|c|}{ ARIMA } & \multirow{2}{*}{ RMSE } \\
\hline$(0$ & $\begin{array}{ll}, 0 & , 0)\end{array}$ & & $(0$ &, 2 & $, 0)$ & & $(1$ & 1 & ,2) & \\
\hline 10 & $, 0,1)$ & 4.3 & $(0$ &, 2 & ,2) & 4.1 & 1 &, 2 & , (0) & Not fitte \\
\hline ( & $, 0 \quad, 2)$ & Not fitted & $(1$ &, 0 & $, 0)$ & Not $f$ & 1 &, 2 & ,1) & 4. \\
\hline (c) & $, 1,0)$ & Not & $(1$ &, 0 & 1 & 4.8 & 1 &, 2 & ) & 4. \\
\hline$(0$ & , 2,0$)$ & Not & $(1$ & 0 & ,2) & Not $\mathrm{f}$ & $(2$ &, 0 & $, 0)$ & Not fit \\
\hline$(0$ & $, 1,1)$ & Not fitted & $(1$ &, 1 & $, 0)$ & Not fit & $(2$ &, 0 & ,1) & 4.4 \\
\hline$(0$ & $, 1,2)$ & 4.7 & $(1$ & $, 1,1$ & & 5.00 & $(2$ &, 0 & ,2) & 4. \\
\hline$(2$ & $, 1,0)$ & Not fitted & $(2$ &, 1 & ,2) & 5.1 & $(2$ &, 2 & ,1) & 4.9 \\
\hline$(2$ & , 1,1$)$ & 4.00 & $(2$ &, 2 & ,0) & Not fitted & $(2$ &, 2 & ,2) & 4.2 \\
\hline
\end{tabular}

Based on Table 1 the researchers note that:

The values of $\mathrm{p}, \mathrm{d}$ and $\mathrm{q}$ are between 0 and 2 only since these values impossible to be in the minus also theses values should not be more than 2 since the estimation of the parameters will be worthless.

RMSE is varied between 4.00 and 5.00 based on the dataset used. Therefore, After the dataset is implemented using the software then ARIMA $(2,1,1)$ was found the best with RMSE $=4.00$.

In some cases ARIMA model is not fitted which means that the estimation of the dataset cannot be done then it should be ignored.

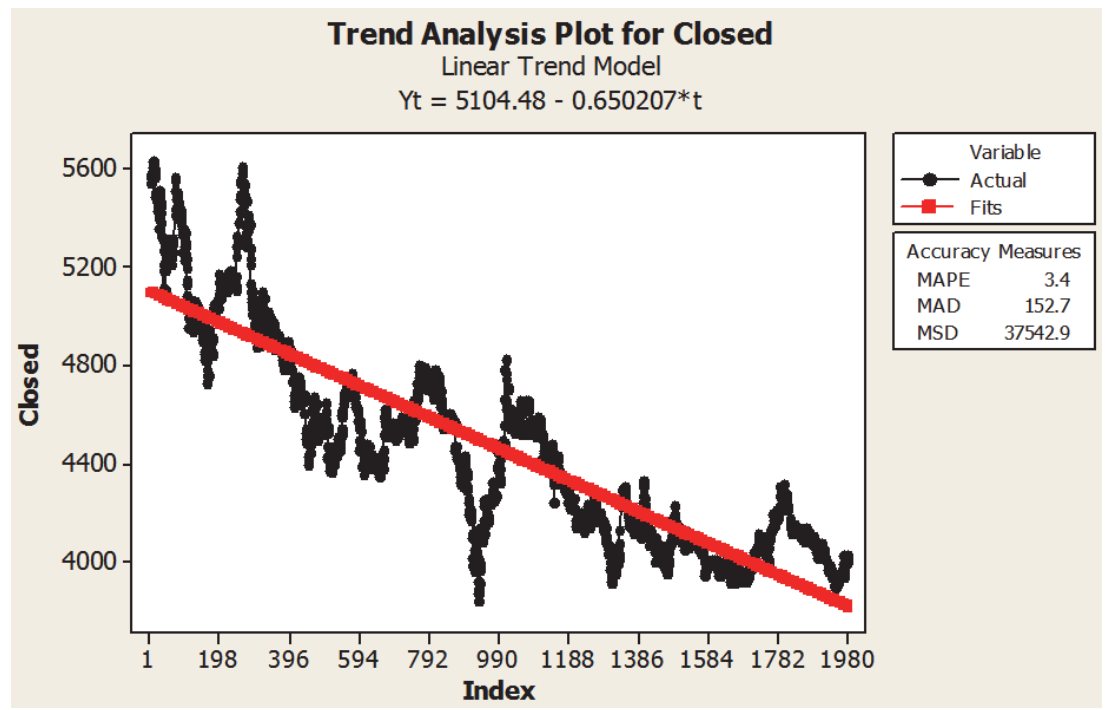

Figure 2. The trend analysis 
The trend analysis as shown in Figure 2 is very important in forecasting processes in order to show the direction of the future values and the stationarity of the dataset. Then finally, the values of ARIMA parameters with its significant level can be summarized as:

$\begin{array}{llllll}\text { Type } & & \text { Coef } & \text { SE Coef } & \text { T } & \text { P-value } \\ \text { MA } & 1 & -1.5371 & 0.0120 & -128.18 & 0.000 \\ \text { MA } & 2 & -0.8955 & 0.0093 & -95.81 & 0.000 \\ \text { Constant } & 4460.78 & 10.04 & 444.10 & 0.000\end{array}$

We notes that all the parameters (MA and the constant term) are significant since the P-value is 0.00 for all the variables which means the selected model is very fit and suitable for forecasting.

\section{Conclusion}

Based on the results in the tables and figures then this paper shows three major results can be summarize as:

The general process of ARIMA model for closed stock market data predicting. The results achieved with best ARIMA model which is ARIMA $(2,1,1)$ with $\mathrm{RMSE}=4.00$ while the other models of the ARIMA has higher than this value. Moreover, the fluctuation of the data set is discussed and all of the outlier values have been detected. These results guide investors in this area to make profitable investment decisions since these results found that ARIMA model can participate reasonably well with emerging forecasting techniques in short term forecasting. The limitation for this model is in using ARIMA model with only short term forecasting. However, in some cases the researchers need to make long term forecasting. As a future work, this model can be implemented for any other type of data such as rainfall data.

\section{References}

Alwadi, R. (2015). Forecasting short term financial data. European Scientific Journal, 11(25), 251-255.

Atsalakis G. S., \& Kimon, P. V. (2009). Forecasting stock market short-term trends using a neuro-fuzzy methodology. Expert Systems with Applications, 36(7), 10696-10707.

Atsalakis, G. S., Dimitrakakis. E. M., \& Zopounidis, C. D. (2011). Elliot wave theory and neuro-fuzzy systems, stock market prediction: The WASP system. Expert Systems with Applications, 38, 9196-9206.

Awajan, A. M., Ismail, M. T., \& Al Wadi, S. (2017). A hybrid EMD-MA for forecasting stock market index. Italian Journal of Pure and Applied Mathematics, 38(1), 1-20.

Awajan, A. M., Ismail, M. T., \& Wadi, S. A. (2017). Forecasting time series using EMD-HW bagging. International Journal of Statistics \& Economics ${ }^{\mathrm{TM}}$, 18(3), 9-21.

Box, G. E. P., \& Jenkins, G. M. (1970). Time series analysis: Forecasting and control, San Francisco: Holden-Day.

Donovan, T. M. O. (1983). Short term forecasting, An introduction to the Box-Jenkins approach, John Wiley \& Sons.

Jaber, J. J., Ismail, N., Wadi, S. A., \& Saleh, M. H. (2017). Forecasting of volatility risk for Jordanian banking sector. Far East Journal of Mathematical Sciences, 101(7), 1491-1507.

Javier, C., Rosario, E., Francisco, J. N., \& Antonio, J. C. (2003). ARIMA models to predict next electricity price. IEEE Transactions on Power Systems, 18(3), 1014-1020.

Khashei, M., Bijari, M., \& Ardali, G. A. R. (2012). Hybridization of autoregressive integrated moving average (ARIMA) with probabilistic neural networks (PNNs). Computers \& Industrial Engineering, 63(1), 37-45.

Khashei, M., Bijari, M., \& Ardali, G.A.R. (2009). Improvement of auto-regressive integrated moving average models using fuzzy logic and artificial neural networks (ANNs). Neurocomputing, 72(4-6), 956-967.

Kyungjoo, L. C., Sehwan, Y., \& John, J. (2007). Neural network model vs. SARIMA model in Forecasting Korean Stock Price Index (KOSPI). Issues in Information System, 8(2), 372-378.

Lee, C., \& Ho, C. (2011). Short-term load forecasting using lifting scheme and ARIMA model. Expert System with Applications, 38(5), 5902-5911.

Maqableh, M., \& Karajeh, H. (2014). Job scheduling for cloud computing using neural networks. 
Communications and Network, 6(3), 191-200.

Maqableh, M., Rajab, L., Quteshat, W., Khatib, T., \& Karajeh, H. (2015). The impact of social media networks websites usage on students' academic performance. Communications and Network, 7(4), 159-171.

Merh, N., Saxena, V. P., \& Pardasani, K. R. (2010). A comparison between hybrid approaches of ANN and ARIMA for Indian stock trend forecasting. Business Intelligence Journal, 3(2), 23-43.

Meyler, A., Kenny, G., \& Quinn, T. (1998). Forecasting Irish inflation using ARIMA models. Central Bank of Ireland Research Department, Technical Paper, 3/RT/1998.

Mitra, S. K. (2009). Optimal combination of trading rules using neural networks. International Business Research, 2(1), 86-99.

Mostafa, M. M. (2010). Forecasting stock exchange movements using neural networks: Empirical evidence from Kuwait. Expert Systems with Applications, 37(9), 6302-6309.

Nochai, R., \& Nochai, T. (2006, June). ARIMA model for forecasting oil palm price. In Proceedings of the 2nd IMT-GT Regional Conference on Mathematics, Statistics and Applications (pp. 13-15).

Pai, P. F., \& Lin, C. S. (2005). A hybrid ARIMA and support vector machines model in stock price forecasting. Omega, 33(6), 497-505.

Sterba \& Hilovska. (2010). The implementation of hybrid ARIMA neural network prediction model for aggregate water consumption prediction. Aplimat- Journal of Applied Mathematics, 3(3), 123-131.

Tabachnick, B. G., \& Fidell, L. S. (2001). Using multivariate statistics, 4th ed., Person Education Company, USA.

Wang, C. (2011). A comparison study of between fuzzy time series model and ARIMA model for forecasting Taiwan Export. Expert System with Applications, 38(8), 9296-9304.

Wang, J. J., Wang, J. Z., Zhang Z. G., \& Guo S. P. (2012). Stock index forecasting based on a hybrid model. Omega, 40, 758-766.

Wei, L. Y. (2013). A hybrid model based on ANFIS and adaptive expectation genetic algorithm to forecast TAIEX. Economic Modelling, 33, 893-899.

\section{Copyrights}

Copyright for this article is retained by the author(s), with first publication rights granted to the journal.

This is an open-access article distributed under the terms and conditions of the Creative Commons Attribution license (http://creativecommons.org/licenses/by/4.0/). 